\title{
Treatment of Class II Malocclusion With Removable Functional Appliances: A Narrative Review
} \author{
Mohammad Khursheed Alam ${ }^{5}$ \\ ${ }^{1}$ Department of Orthodontics, The Dental Centre, Nairobi, Kenya \\ 2 Department of Orthodontic, Sindh Institute of Oral Health Sciences, \\ Jinnah Sindh Medical University, Karachi, Pakistan \\ ${ }^{3}$ Department of Orthodontics, Dr. Ishrat Ul Ibad Khan Institute of Oral \\ Health Sciences, Dow University of Health Sciences, Karachi, \\ Pakistan \\ ${ }^{4}$ Department of Prosthodontics and Dental Implantology, College of \\ Dentistry, King Faisal University, KSA, Saudi Arabia \\ ${ }^{5}$ Department of Orthodontic, College of Dentistry, Jouf University, \\ Sakaka, Aljouf, KSA, Saudi Arabia \\ Eur J Gen Dent 2021;10:170-175.
}

Saima Nizar Hirji ${ }^{10}$ Irfan Qamruddin ${ }^{2} \quad$ Muhammad Adeel Mudassar ${ }^{3} \quad$ Zohaib Khurshid ${ }^{4}$

Address for correspondence Saima Nizar Hirji, BDS, MSc, Department of Orthodontics, The Dental Centre, Parkwest Office Suites, 8C, TRV Centre, 3rd Parklands, Nairobi, Kenya

(e-mail: saima.hirji@icloud.com).

Zohaib Khurshid, Department of Prosthodontics and Dental Implantology, College of Dentistry, King Faisal University, KSA, Saudi Arabia (e-mail: drzohaibkhurshid@gmail.com).

\author{
Abstract \\ Keywords \\ - removable functional \\ appliance \\ - twin block \\ - monoblock appliance \\ - Class II malocclusion \\ and occlusal \\ adjustment
}

Around half of all malocclusions that need orthodontic treatment are Class II in nature. Patients with Class II malocclusion primarily seek treatment for aesthetic improvement. Most of the skeletal Class II malocclusions are because of mandibular deficiency, and can be best treated during the growing phase of development by removable functional appliances. The objective of this review is to evaluate and compare skeletal and dentoalveolar effects of various removable functional appliances in the treatment of Class II malocclusion. Manual and electronic databases were searched, and out of 5,711 articles, 221 abstracts were shortlisted and reviewed. A total of 19 articles that fulfilled the selection criteria was then retrieved and analyzed. A significant increase in mandibular length and dentoalveolar effects with an increase in vertical dimension in a short time was observed with Twin-Block appliance treatment, followed by Bionator appliance treatment. The long-term stability of results achieved with Twin-Block appliance treatment is still questionable. In addition, Frankel appliance treatment effects are more skeletal in nature, with better control in the vertical dimension. However, it takes a more extended treatment duration to produce similar effects. Based on available evidence, we are convinced that removable functional appliances are valuable tools for correction of the Class II malocclusion at a growing age with a horizontal growth pattern.

\section{Introduction}

Around half of all malocclusions that need orthodontic treatment are Class II in nature. ${ }^{1}$ Patient with Class II malocclusion primarily seeks treatment for aesthetic improvement. Most of the skeletal Class II malocclusions are because of mandibular deficiency, and they can be best
DOI https://doi.org/ $10.1055 / \mathrm{s}-0041-1736379$ ISSN 2278-9626.

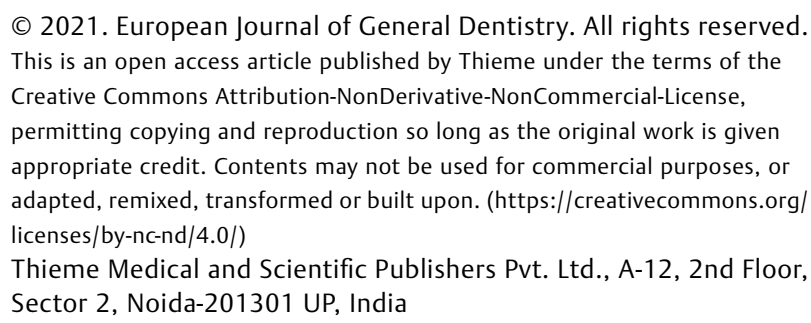


treated during the growing phase of development by removable functional appliances. ${ }^{2}$ Since the early 20th century, removable functional appliances were considered a significant part of orthodontic treatment. These appliances target the growth of the mandible and alter its posture to produce forces by stretching the muscles and soft tissues. This brings out a change in the neuromuscular environment, thereby leading to bone remodeling and growth modification. However, the amount of change produced by them is still controversial. ${ }^{3}$ Many studies have been conducted in the past to evaluate the effects of these appliances on the growth of the mandible. Animal studies have shown that these functional appliances increase the proliferation of cells within condylar cartilage and cause bone remodeling at the anterior border of the glenoid fossa. ${ }^{4-7}$ However, the applicability of animal studies on humans is debatable due to the differences in duration of growth, morphology, and physiology. ${ }^{3}$ In the past two decades, several clinical trials were done on humans claiming that functional that functional appliance therapy results in a small but significant increase in the growth of the mandible. ${ }^{8-10}$ Literature has also shown that these appliances are most successful in cases with an overjet of up to $11 \mathrm{~mm}$, increased overbite, active facial growth, and good cooperation. ${ }^{11}$ Some authors believe that these appliances increase the length of the mandible due to the growth of ramus, and others believe that they only cause repositioning of the teeth. ${ }^{12-16}$ In addition, to increase the length of the mandible and incorporate change in the inclination of incisors, relocation of the condyle and increase in the vertical dimension to correct sagittal discrepancy should not be ignored as treatment effects. Mamandras and Allen noticed in their study that patients with a small mandible in comparison to a control group may benefit more from functional appliance therapy than patients with a normal size of mandibles. Hence, it works out best in subjects with delayed growth. ${ }^{13}$ Taking into account all the theories, limited quality and heterogeneity in available studies generate a demand to critically analyze relevant literature for best evidence about the efficacy of various removable functional appliances.

The article is a narrative review of the evaluation and comparison of skeletal and dentoalveolar effects of various removable functional appliances in subjects with Class II malocclusion.

\section{History of Removable Functional Appliances}

Bone is one of the hardest tissues in the human body, and it is also the most responsive to environmental stimuli. Removable functional appliances are orthopedic tools that capitalize the patient's functional forces to achieve orthodontic and orthopedic correction of dentofacial anomalies. They influence the facial skeleton of a growing child in the condylar, dentoalveolar, and sutural areas. According to Wolff and Roux, bone is plastic in nature. Changes in functional stress produce changes in internal bone architecture and shape. ${ }^{1}$ Removable functional appliances are designed to correct anteroposterior jaw dysplasia, and they act on teeth and
Table 1 History of RFA

\begin{tabular}{|l|l|c|}
\hline Inventor's name & Appliance name & Year \\
\hline Kingsley & Kingsley plate & 1880 \\
\hline Holtz & Hawley bite plate & 1900 \\
\hline Pierre robin & Monoblock & 1902 \\
\hline Andresen & Activator & 1908 \\
\hline H.P. Bimler & Bimler's appliance & 1949 \\
\hline Dr Hugo Stockfisch & Kinetor & 1950 \\
\hline Frankel & Frankel's appliance & 1950 \\
\hline Balter & Bionator & 1979 \\
\hline Clark & Twin-Block & 1980 \\
\hline
\end{tabular}

Abbreviations: RFA, removable functional appliances.

orofacial musculature to transmit, eliminate and guide natural forces. ${ }^{17}$ It has less potential for relapse compared with fixed appliance treatment.

Kingsley in 1880 introduced the bite-jumping appliance in orthodontics. The mandible's forward positioning is the critical feature in functional appliance treatment, which results in the sagittal correction of malocclusion. This feature was in the contradiction to the early bite-jumping appliance, where condyle fossa relationship was not altered. The issue with the Kingsley appliance was the difficulty in guiding the mandible in a forward position. Holtz later modified the Kingsley plate and named it the Hawley bite plate, which was used as a splint in managing temporomandibular (TMD) cases in the past. After that, Viggo Andresen, in 1908, provided a vertical extension to the bite plate to get an appliance in contact with the lingual surface of mandibular molars, and named it Activator. The Activator appliance's pitfalls were the jiggling forces created as a result of dual bite formation and proclination of lower incisors.

Moreover, it was a bulky appliance, and it was advised to wear only at night. In the early 20th century, Pierre Robin introduced a plastic Monoblock appliance that works as a passive anterior mandible positioning device, used in neonates with micromandibular development, to prevent glossoptosis. Later, more popular appliances were introduced, which included Bionator, Frankel and Twin-Block (-Table 1). ${ }^{17}$

\section{Treatment Principles of Removable Functional Appliances}

Treatment principles of removable functional appliances include force application, which results in alteration of the form, with secondary adaptation in function and by force elimination, to allow optimal development and removal of restrictive forces. Patients suffering from neuromuscular disorders like polio or cerebral palsy cannot be treated with removable functional appliances. According to Lischer, if compensatory, adaptive lip and tongue function could exacerbate excessive overjet in Class II type malocclusions, and if abnormal, swallowing and prolonged finger-sucking 
habits could create an anterior open bite and narrow arches. Could not the same muscles be used to correct these and other problems? ${ }^{1}$

Holding the lower jaw forward for long enough can reverse the deleterious effects of trapped lower lips, incompetent lips, and abnormal respiration. Sagittal changes observed by the use of the removable functional appliances are results of increased activity of protractor and elevator muscles with concomitant relaxation and stretching of retractor muscles. Under new functional stresses, changes in muscle patterns harvest changes in the bony structure. Unloaded condyles in protracted mandible position are hypothesized to promote condylar growth in upward and backward direction. Research conducted by Stutzmann demonstrates the effects of removable functional appliance treatment as an actual change in internal condylar structure, with a more posterior directional orientation of the trabeculae. Some evidence also exists in relation to minor retardation of maxillary sagittal growth. The vertical growth can be controlled by covering occlusal surfaces of teeth with acrylic to prevent the eruption of posterior teeth. ${ }^{1}$ The forward posturing of condyles results in activation of the superior head of the lateral pterygoid muscle, which plays a decisive role in the growth of the mandible. Monoblock and Twin-Block appliances have different modes of action. A rigid one-piece appliance does not cause shortening of muscles but develops high tension, which therefore requires high forces; as a result, contractions arising are isometric in nature. A two-piece appliance causes muscle shortening, and it requires a low magnitude of force, which produces isotonic contractions. Consequently, it requires more wearing time to get equally effective as one-piece appliance. Total sagittal change is a combination of an incremental increase in condylar growth, a more favorable direction of growth, repositioning and adaptation of the fossa and articular eminence. Some degree of withholding of maxillary dentoalveolar area is because of the appliance design, duration of wear, or addition of extraoral traction device.

\section{Construction Bite}

The mode of forces applied, magnitude, and direction depend on three-dimensional dislocation of the condyle, which depends on construction bite. Mandible must be dislocated from the postural resting position in at least one direction (sagittal or vertical). If the magnitude of forwarding advancement is greater, then the vertical opening should be minimal, not to overstretch the muscles. If the sagittal forces are around 31 to $395 \mathrm{~g}$, then the vertical forces should be lower, approximately 70 to $175 \mathrm{~g}$. If an excessive vertical opening is needed, mandibular advancement should be controlled. Overactivation results in reduced efficacy of the appliance. As a general rule, advancement should be $3 \mathrm{~mm}$ or more to produce a change in a sagittal relationship. The current use of functional appliances mostly follows the protocol of small bite opening and incremental advancement to correct Class II, Class III and open bite malocclusion - Fig. 1a-h. A good technique to record
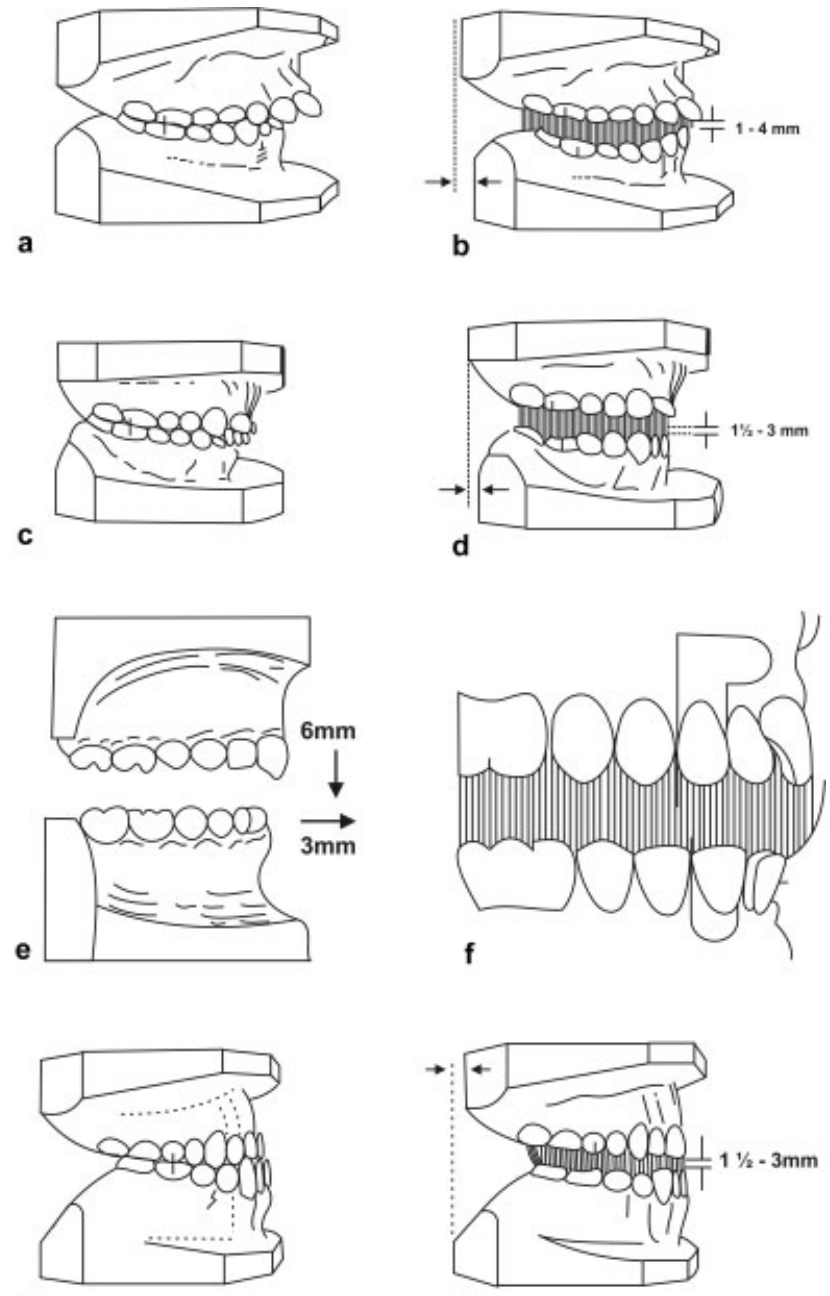

g

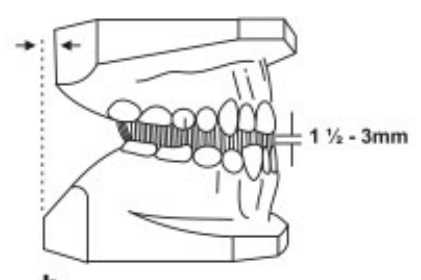

h

Fig. 1 Construction of bite in Class II, Class III, and open-bite malocclusion: ( $\mathbf{a}$ and $\mathbf{b}$ ) is construction of bite plane in Class II division I deep bite and increased overjet correction; (c and $\mathbf{d}$ ) is construction bite in Class II division II deep bite with normal overjet; (e and $\mathbf{f}$ ) is construction bite in open-bite malocclusion; and $(\mathbf{g}$ and $\mathbf{h})$ is construction bite in Class III reverse overjet.

construction bite is to ask the patient to move the mandible forward as far as possible and then drop back 3 to $4 \mathrm{~mm}$.

\section{Instructions for Wearing the Appliance}

Daytime wear enhances the frequency of deglutition and phasic muscle activity. Telemetric studies have shown that the function will not improve while wearing an appliance only during sleep timing. Most of the time, forward posturing of the condyles does enhance metabolic action in the TMJ, which may account for enhanced growth of the condyle and posterior fossa wall proliferation. Functional activity and interarch contact also help in the correction of Class II malocclusion with the use of the Twin-Block appliance. Thus, it is advised that a patient is instructed to wear Twin-Block all the time and remove them only for cleaning purposes, increasing the duration of wear results in rapid correction of malocclusion. 


\section{Data Collection Procedure for Review}

Electronic databases were searched for four keyword combinations. A total of 5,711 articles were retrieved from Cochrane, Pub med, Science direct and Digibib, and 221 abstracts were shortlisted and reviewed. Duplicate articles were removed, followed by reading and analyzing of abstracts. Nineteen articles were retrieved and analyzed. All selected articles had comparable control groups.

\section{Observations}

\section{Twin-Block Appliance Treatment}

Kevin in 2003 declared insignificant favorable skeletal effects in the treated group, ${ }^{18}$ whereas, studies done by Trenouth, Christine, and Saikoski showed statistically significant skeletal effects (reduction in A point, nasion, B point [ANB] angle and increase in mandibular length). ${ }^{19-21} \mathrm{~A}$ study done by Singh showed an increase in condylar growth, coronoid process remodeling and osteogenesis in a corpus, and in the dentoalveolar region, resulting in skeletal growth of mandible and correction of Class II malocclusion. ${ }^{22}$ Kanoknart found an alteration in condylar growth direction in the treated group, which helps in the correction of Class II. ${ }^{23}$ Although a study by Christine showed insignificant vertical effects of the Twin-Block appliance, ${ }^{20}$ Dauravu found maxillary restriction effects. Saikoski found insignificant results in this regard. ${ }^{24}$ In five studies, significant dentoalveolar effects (change of incisor inclinations, overjet reduction and molar relation correction) in addition to skeletal effects have been observed, which helped early correction of Class II malocclusion with Twin-Block appliance. ${ }^{18-24}$

\section{Frankel Appliance Treatment}

All studies have proven significant skeletal effects of appliance. Studies done by Perillo, James, Hayan, David, and Angelieri showed an increase in mandibular length, ${ }^{14,25-28}$ whereas a study done by Lucia showed ramus remodeling. ${ }^{29}$ A study done by James showed, in addition to an increase in mandibular length, the Frankel appliance cause a significant increase in the vertical dimension and slight maxillary restriction effects (point A) that resulted in correction of malocclusion. ${ }^{14}$ Four studies have shown significant dentoalveolar effects in addition to the skeletal effects of Frankel appliance. ${ }^{14,26-29}$

\section{Bionator Appliance Treatment}

A single study done by Jonatha is included in this group. ${ }^{30}$ Treated group exhibited both skeletal and dental effects. Also, control in growth direction was observed, which resulted in a reduction in facial convexity. Reduced eruption of upper molars and less increase in vertical dimension were seen in the treated group. Thus, the open-bite Bionator proved to be an effective appliance in correcting Class II in high-angle cases.

\section{Comparison of Twin-Block and Frankel Appliances}

The results of Linda in 1999 showed Twin-Block having pronounced skeletal and dentoalveolar effects, while Frankel appliance produced entirely skeletal effects. ${ }^{31}$ Significant skeletal effects were observed in both treated groups. A greater increase in mandibular length was observed in Twin-Block-treated group (Twin-Block $3 \mathrm{~mm}$, Frankel $1.9 \mathrm{~mm}$ than controls). An increase in vertical dimension was seen in both treated groups (more in Twin-Block than Frankel). No maxillary restriction was found in any treated group. Dentoalveolar effects were more pronounced in the Twin-Block group; however, both treated groups showed retroclination of upper incisors, reduction of overjet and overbite. The Twin-Block group showed upper molar distalization in addition to other dental effects.

\section{Comparison of Bionator and Frankel Appliance}

Marcio, in 2002, observed major dentoalveolar effects with a significant component of skeletal effect in both treated groups. A greater increase in mandible length and vertical dimension was observed in the Bionator group. An insignificant maxillary effect was found in both treated groups. ${ }^{32}$

\section{Comparison of Twin-Block and Monoblock Appliance}

Dalci et al observed greater changes in growth patterns in the Activator group, whereas Tumer observed more in his study in the Twin-Block group. Both Dalci et al and Tumer showed similar skeletal effects by both appliances. Jena observed a significant increase in mandible length only in Twin-Blocktreated group. All studies on tested appliances showed similar dentoalveolar effects. However, Dalci O, 2014; observed major differences in treatment duration in the two treated groups. A very fast correction was achieved by the Twin-Block appliance. ${ }^{12,33,34}$

\section{Discussion}

The efficacy of removable functional appliance in the treatment of Class II malocclusion is still a subject of controversy. This review includes data from 19 studies (1 randomized control trial, 9 clinical trials, 9 retrospective studies). Cephalometric changes were assessed in 1045 patients, including a control group. Appliances used in selected studies were Clarks' Twin-Block, Frankel regulator, Bionator, Monoblock, and Activator. In the present review, only those studies have been included that had considered either similar or historical control groups. All studies without control groups were removed at the initial stage of article selection.

The result of the current review needs to be analyzed with caution due to the limitations of included studies. Diverse linear and angular measurements were used in different studies to quantify treatment effects. The variety of measurements used in selected studies makes it challenging to compare their findings with each other. In the current review, the following measurements were used: angle between sellanasion-A point (SNA), angle between sella-nasion-B point (SNB), ANB, mandibular length, overjet and inclination of incisors. Furthermore, number of operators conducting studies and tracing X-rays and their variable level of experience potentially introduce bias and the issue of interexaminer reliability. Moreover, the difference in methods of study and 
statistical tests adds more confusion in the interpretation of stated results. Thus, the results of the existing review are more generalized and may not be evaluated based on individual variations, ethnic variation, gender dimorphism, treatment protocol, patient compliance, or biological response.

We observed a statistically significant increase in mandibular length and dentoalveolar effects with an increase in vertical dimension with Twin-Block followed by Bionator treatment. Frankel appliance effects are more skeletal in nature with better control in the vertical dimension. However, it takes a longer treatment time to produce similar effects. Meta-analysis done by Elvira et al included four articles in his study (338 patients, 168 treated, and 170 control) and showed statistically significant increase of $1.79 \mathrm{~mm}$ in annual mandibular growth in the treated group. However, clinical improvement was found to be insignificant. ${ }^{35}$ We also found a statically significant skeletal treatment effects of removable functional appliances, depicted as a decrease in ANB and increase in SNB, mandibular length and condylar growth. The soft-tissue effect was not evaluated in the current study.

A meta-analysis done by Vaid et al in 2014 included 24 articles on removable functional appliances and 7 articles on fixed functional appliances. His study showed a statistically significant increase in mandibular length, and an insignificant effect was observed on the maxilla with use of the removable functional appliances. ${ }^{36}$ Results of the present review are in agreement with Vaid's study. However, research done by Nucera et al included 14 articles. A slight inhibitory effect on the sagittal growth of the maxilla was observed. However, no effect was seen on the rotation of the maxillary plane. Literature supports that maxillary restriction effect is more pronounced with treatment with fixed functional appliance. ${ }^{37}$

A study done by Madurantakam et al included 17 articles involving 1031 patients with a mean age of 10.6 years. He observed both statistically significant skeletal as well as dentoalveolar effects with the use of removable functional appliances. Results showed a reduction in SNA ( -0.26 degree/year), increase in SNB (0.62 degree/year), upper incisor retroclination (-6.33 degree/year), and mandibular teeth proclination (1.37 degree/year). ${ }^{38}$ More dental effects were detected than skeletal to achieve correction of Class II malocclusion. Metaanalysis done by Koretsi et al, including 17 studies $(1,031$ subjects) with a mean age of 10.6 years, also showed limited skeletal effects compared with a control group. They found most of treatment effects were dentoalveolar in nature. ${ }^{39}$ In the current review, we observed similar findings. However, it also depends on the type of removable functional appliance used. We found combined treatment effects (skeletal and dentoalveolar) produced by Twin-Block followed by Bionator. Frankel appliance produces more skeletal effects and requires a longer duration of treatment to achieve similar results.

Sagittal correction of Class II malocclusion is associated with potential side effects of increasing vertical dimension. Thus, removable functional appliances were good in the treatment of patients with horizontal growth pattern. Some selected studies had measured facial heights and hence given us insights on rotational changes of the mandible. However, it has been observed facial height changes potentially mask or exaggerate the true sagittal changes. A meta-analysis done by Bertl et al found similar results and discovered that the biggest increase in vertical dimension was recorded for Activator. ${ }^{40}$ In the current review, an increase in vertical dimension was more associated with the Monoblock appliance followed by the Twin-Block appliance. However, the Frankel appliance demonstrated relatively less increase in the vertical dimension.

Five studies were included in the meta-analysis performed by Adriana et al. The overall increase in mandibular length was $1.53 \mathrm{~mm}$ in comparison to the nontreated group. The Sander Bite Jumping Monoblock reported the greatest gain in mandibular length, followed by Twin-Block, Bionator, Activator and Frankel appliance. It was concluded that all removable functional appliances, aiming to gain mandibular length, are beneficial. Sander Bite Jumping was observed to be the most effective device to gain mandibular length. ${ }^{41}$

\section{Clinical Implications}

Based on the current knowledge of the growth of the bony facial skeleton, specific treatment objectives and targeted approaches should be used for the correction of malocclusion. Thus, focuses of treatment should be based on an individual diagnosis of each patient. Taking into account all the cosmetic, functional and dental needs, the combination and customization of the removable functional appliance should be constructed and given to the patient to achieve the best possible outcome of treatment. Thus, removable functional appliance therapy does help in the correction of Class II malocclusion. However, the key to success is careful case selection, right age selection to begin the treatment, use of the appropriate type of removable functional appliance, and the use of a combination of other appliances or customization of the current appliance, as per need basis is fundamental.

\section{Summary}

A statistically significant increase in mandibular length and dentoalveolar effects with an increase in vertical dimension in a short time was observed with Twin-Block treatment followed by Bionator treatment. The long-term stability of results achieved with Twin-Block treatment is still questionable. Frankel appliance effects are more skeletal in nature with better control in the vertical dimension. However, it takes more treatment time to produce similar effects. Based on the available evidence, it shows functional appliances are a valuable tool for correction of Class II malocclusion at a growing age with horizontal growth patterns. Long-term double-blinded, prospective, randomized control trials are needed to confirm the findings of the current study.

Conflict of Interest

None declared.

\section{References}

1 Graber TM, Moss ML, Aronson SL, Enlow DH. Introduction. In: Graber TM, Rakosi T, Petrovic AG, eds. Dentofacial Orthopedics With Functional Appliances. USA: Mosby; 1997 
2 McNamara JA Jr. Components of Class II malocclusion in children 8-10 years of age. Angle Orthod 1981;51(03):177-202

3 Martyn TC, Andrew TD. Handbook of Orthodontics. 8th ed. USA: Mosby; 2010

4 Charlier JP, Petrovic A, Herrmann-Stutzmann J. Effects of mandibular hyperpropulsion on the prechondroblastic zone of young rat condyle. Am J Orthod 1969;55(01):71-74

5 McNamara JA Jr, Bryan FA. Long-term mandibular adaptations to protrusive function: an experimental study in Macaca mulatta. Am J Orthod Dentofacial Orthop 1987;92(02):98-108

6 Voudouris JC, Woodside DG, Altuna G, et al. Condyle-fossa modifications and muscle interactions during Herbst treatment, Part 2. Results and conclusions. Am J Orthod Dentofacial Orthop 2003; 124(01):13-29

7 Robert JH, David SC. Regulation of growth in mandibular condylar cartilage. Semin Orthod 2005;11:209-218

8 Dolce C, McGorray SP, Brazeau L, King GJ, Wheeler TT. Timing of Class II treatment: skeletal changes comparing 1-phase and 2-phase treatment. Am J Orthod Dentofacial Orthop 2007;132(04):481-489

9 O'Brien K, Wright J, Conboy F, et al. Effectiveness of early orthodontic treatment with the Twin-block appliance: a multicenter, randomized, controlled trial. Part 2: Psychosocial effects. Am J Orthod Dentofacial Orthop 2003;124(05):488-494, discussion 494-495

10 Tulloch JF, Proffit WR, Phillips C. Outcomes in a 2-phase randomized clinical trial of early Class II treatment. Am J Orthod Dentofacial Orthop 2004;125(06):657-667

11 Barton S, Cook PA. Predicting functional appliance treatment outcome in Class II malocclusions-a review. Am J Orthod Dentofacial Orthop 1997;112(03):282-286

12 Jena AK, Duggal R, Parkash H. Skeletal and dentoalveolar effects of Twin-block and bionator appliances in the treatment of Class II malocclusion: a comparative study. Am J Orthod Dentofacial Orthop 2006;130(05):594-602

13 Mamandras AH, Allen LP. Mandibular response to orthodontic treatment with the Bionator appliance. Am J Orthod Dentofacial Orthop 1990;97(02):113-120

14 McNamara JA Jr, Bookstein FL, Shaughnessy TG. Skeletal and dental changes following functional regulator therapy on Class II patients. Am J Orthod 1985;88(02):91-110

15 Schulhof RJ, Engel GA. Results of Class II functional appliance treatment. J Clin Orthod 1982;16(09):587-599

16 Eirew HL. The bionator. Br J Orthod 1981;8(01):33-36

17 Macey-Dare LV, Nixon F. Functional appliances: mode of action and clinical use. Dent Update 1999;26(06):240-244, 246

18 O'Brien K, Wright J, Conboy F, et al. Early treatment for Class II Division 1 malocclusion with the Twin-block appliance: a multicenter, randomized, controlled trial. Am J Orthod Dentofacial Orthop 2009;135(05):573-579

19 Trenouth MJ. Cephalometric evaluation of the Twin-block appliance in the treatment of Class II Division 1 malocclusion with matched normative growth data. Am J Orthod Dentofacial Orthop 2000;117(01):54-59

20 Mills CM, McCulloch KJ. Posttreatment changes after successful correction of Class II malocclusions with the twin block appliance. Am J Orthod Dentofacial Orthop 2000;118(01):24-33

21 Saikoski LZ, Cançado RH, Valarelli FP, de Freitas KM. Dentoskeletal effects of Class II malocclusion treatment with the Twin Block appliance in a Brazilian sample: a prospective study. Dental Press J Orthod 2014;19(01):36-45

22 Singh GD, Clark WJ. Localization of mandibular changes in patients with Class II division 1 malocclusions treated with twin-block appliances: finite element scaling analysis. Am J Orthod Dentofacial Orthop 2001;119(04):419-425

23 Chintakanon K, Sampson W, Wilkinson T, Townsend G. A prospective study of Twin-block appliance therapy assessed by magnetic resonance imaging. Am J Orthod Dentofacial Orthop 2000;118(05):494-504
24 Dauravu LM, Vannala V, Arafath M, Singaraju GS, Cherukuri AS, Mathew A. The assessment of sagittal changes with twin block appliance in patients with decelerating growth phase. JCDR Bd 2014;8(12):ZC81-ZC84

25 Perillo L, Johnston LE Jr, Ferro A. Permanence of skeletal changes after function regulator (FR-2) treatment of patients with retrusive Class II malocclusions. Am J Orthod Dentofacial Orthop 1996; 109(02):132-139

26 Haynes S. A cephalometric study of mandibular changes in modified function regulator (Fränkel) treatment. Am J Orthod Dentofacial Orthop 1986;90(04):308-320

27 Freeman DC, McNamara JA Jr, Baccetti T, Franchi L, Fränkel C. Long-term treatment effects of the FR-2 appliance of Fränkel. Am J Orthod Dentofacial Orthop 2009;135(05):570.e1-570.e6, discussion 570-571

28 Angelieri F, Franchi L, Cevidanes LH, Scanavini MA, McNamara JA Jr. Long-term treatment effects of the FR-2 appliance: a prospective evalution 7 years post-treatment. Eur J Orthod 2014;36(02):192-199

29 Cevidanes LH, Franco AA, Scanavini MA, Vigorito JW, Enlow DH, Proffit WR. Clinical outcomes of Fränkel appliance therapy assessed with a counterpart analysis. Am J Orthod Dentofacial Orthop 2003;123(04):379-387

30 Weinbach JR, Smith RJ. Cephalometric changes during treatment with the open bite bionator. Am J Orthod Dentofacial Orthop 1992;101(04):367-374

31 Toth LR, McNamara JA Jr. Treatment effects produced by the twinblock appliance and the FR-2 appliance of Fränkel compared with an untreated Class II sample. Am J Orthod Dentofacial Orthop 1999;116(06):597-609

32 De Almeida MR, Henriques JF, Ursi W. Comparative study of the Fränkel (FR-2) and bionator appliances in the treatment of Class II malocclusion. Am J Orthod Dentofacial Orthop 2002;121(05): 458-466

33 Dalci O, Altug AT, Memikoglu UT. Treatment effects of a twin-force bite corrector versus an activator in comparison with an untreated Class II sample: a preliminary report. Aust Orthod J 2014;30 (01):45-53

34 Tümer N, Gültan AS. Comparison of the effects of monoblock and twin-block appliances on the skeletal and dentoalveolar structures. Am J Orthod Dentofacial Orthop 1999;116(04):460-468

35 Marsico E, Gatto E, Burrascano M, Matarese G, Cordasco G. Effectiveness of orthodontic treatment with functional appliances on mandibular growth in the short term. Am J Orthod Dentofacial Orthop 2011;139(01):24-36

36 Vaid NR, Doshi VM, Vandekar MJ. Class II treatment with functional appliances: A meta-analysis of short-term treatment effects. Semin Orthod 2014;20:324-338

37 Nucera R, Lo Giudice A, Rustico L, Matarese G, Papadopoulos MA, Cordasco G. Effectiveness of orthodontic treatment with functional appliances on maxillary growth in the short term: A systematic review and meta-analysis. Am J Orthod Dentofacial Orthop 2016;149(05):600-611.e3

38 Madurantakam P. Removable functional appliances effective in patients with Class II malocclusions. Evid Based Dent 2016;17 (01):27-28

39 Koretsi V, Zymperdikas VF, Papageorgiou SN, Papadopoulos MA. Treatment effects of removable functional appliances in patients with Class II malocclusion: a systematic review and meta-analysis. Eur J Orthod 2015;37(04):418-434

40 Bertl MH, Mandl C, Crismani AG. Do functional orthodontic appliances stimulate mandibular growth in Class II division 1 patients. International journal of stomatology \& occlusion medicine Bd 2011;4(02):6-28

41 Santamaría-Villegas A, Manrique-Hernandez R, Alvarez-Varela E, Restrepo-Serna C. Effect of removable functional appliances on mandibular length in patients with Class II with retrognathism: systematic review and meta-analysis. BMC Oral Health 2017;17(01):52 